\title{
LIQUID CHROMATOGRAPHY METHOD FOR THE SIMULTANEOUS QUANTIFICATION OF FAT SOLUBLE VITAMINS IN FISH TISSUE
}

\author{
Dobreva D., B. Galunska ${ }^{1}$, M. Stancheva \\ Department of Chemistry, ${ }^{1}$ Department of Biochemistry, Molecular medicine and Nutrigenomics, \\ Medical University of Varna
}

Reviewed by: assoc. prof. L. Macedonski

\begin{abstract}
The aim of the present study was to develop simple and accurate small-scale method for simultaneous determination of retinol, $\alpha$-tocopherol, ergocalciferol, and cholecalciferol in edible fish tissue. High performance liquid chromatography was the method of choice since it provides rapid, sensitive and accurate detection of all four fat-soluble vitamins and requires small amounts of sample. The sample preparation procedure was improved using single reaction tube for both hydrolysis and extraction of the analytes. The overall recovery exceeded $76 \%$ for retinol and ergocalciferol, $93 \%$ for alpha-tocopherol, and $83 \%$ for cholecalciferol. The method precision (relative standard deviation) was below $10 \%$ for all analytes. The method was verified on real fish tissue samples and the results for the tested fat-soluble vitamin contents were in a good agreement with the data given by other authors.
\end{abstract}

Key words: fat soluble vitamins, HPLC, fish tissue

\section{INTRODUCTION}

Lipids of marine fish species are rich source of fat soluble vitamins, related to a diversity of biologically important processes in human body. Vitamin A (retinol), takes place in photoreception, regulates gene expression and cell division, bone growth, reproduction. The biologically active isomer of vitamin $\mathrm{E}$ - alpha-tocopherol acts as antioxidant protecting membrane structures and lipoproteins from oxidation. Vitamin $\mathrm{D}_{3}$ (cholecalciferol) and its plant isomer vitamin $\mathrm{D}_{2}$ (ergocalciferol) are of vital importance for regulation of calcium and phosphate homeostasis.

Fat-soluble vitamins have been determined so far, in many different samples, by a variety of techniques. Among them the most widely applied are the chromatographic techniques mainly HPLC, which provides rapid, sensitive and accurate methods for vitamin determination and has the advantages of solvent economy and easy coupling with other techniques. It also requires small amounts of sample. However, most of the already reported methods measure individual vitamin content in fish tissue homogenates $(1,3,9,12,14,15)$. Mobile phases consisting of mixtures of three or four types of solvents or phosphate buffers have been reported $(2,11,12,13)$. Detection modes involved in

Address for correspondence:

D. Dobreva, Dept. of Chemistry, Medical University - Varna,

55 "Marin Drinov" Str, 9000, Varna

e-mail: didobreva@gmail.com the determination of fat-soluble vitamins include UV, diode array $(11,15)$ fluorimetric $(14,17)$, and electrochemical (12), as well as MS detection $(3,6)$. Concerning sample preparation, it is recommended to use short time and gentle extraction methods, sometimes in a darkened place, since these vitamins are unstable during common procedures. The aim of the present work was to develop a simple, fast and accurate method for simultaneous determination of four fat-soluble vitamins: retinol $(A)$, cholecalciferol $\left(D_{3}\right)$, ergocalciferol $\left(D_{2}\right)$, and alpha-tocopherol $(E)$ in edible fish tissue.

\section{MATERIAL AND METHODS}

Instrumentation and chemicals: A high-performance liquid chromatograph (Thermo Scientific Spectra SYSTEM) equipped with UV2000 and FL3000 detectors were used. All solvents were of HPLC grade. Methanol and water was obtained by Sigma-AldrichTM, USA. Substances of vitamins A, $D_{3}, D_{2}$ and alpha-tocopherol were all of analytical grade and were supplied by Supelco (Sigma-AldrichTM, USA). Chromatographic conditions: For the separation of the fat-soluble vitamins, RP-column, type ODS2 Hypersil ${ }^{\mathrm{TM}}$ C18 $(250 \mathrm{~mm} \times 4.60 \mathrm{~mm}, 5 \mu \mathrm{m})$, coupled with RP C18 security guard pre-column was used. The column temperature was kept at $25^{\circ} \mathrm{C}$. The mobile phase of the HPLC system consisted of $97 \%$ methanol (solvent A) and 3\% MiliQ water (solvent B). The mobile phase flow rate was 1 $\mathrm{ml} / \mathrm{min}$ and the injection volume each time was $20 \mu \mathrm{l}$. 
Retinol, cholecalciferol, and ergocalciferol were monitored by UV detection at $\lambda_{\max }=325 \mathrm{~nm}$, and $265 \mathrm{~nm}$, respectively. Alpha-tocopherol was detected by fluorescence at $\lambda_{\mathrm{ex}}=288 \mathrm{~nm}$ and $\lambda_{\mathrm{em}}=332 \mathrm{~nm}$. The chromatographic conditions were chosen in terms of peak shape, column efficiency, chromatographic analysis time, selectivity, and resolution. as a mobile phase. Retention times (tR) were as follows: retinol $\mathrm{tR}=5.36 \mathrm{~min}$, ergocalciferol $\mathrm{tR}=13.97 \mathrm{~min}$, cholecalciferol $\mathrm{tR}=15.06 \mathrm{~min}$, and alpha-tocopherol $\mathrm{tR}=$ $16.95 \mathrm{~min}$. Resolution factors were greater than unity indicating a sufficient separation. Figure 1 shows the chromatographic profiles of a standard mixture of four examined vitamins.
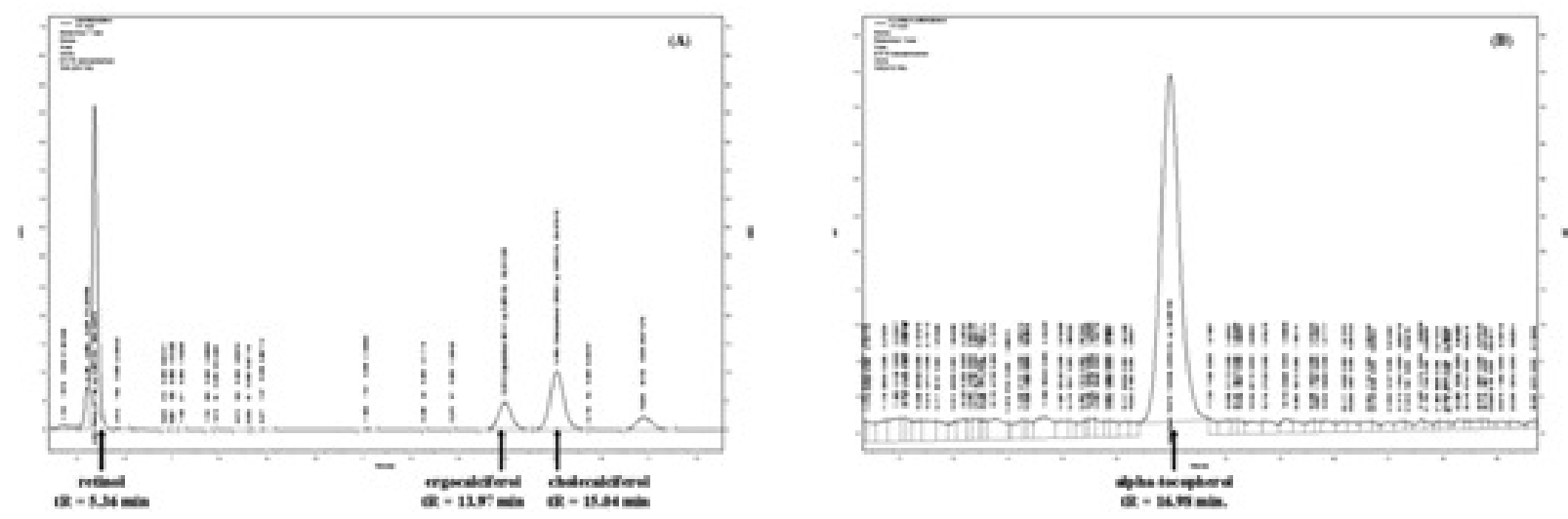

Fig.1. HPLC chromatograms of a mixture of standards solutions of retinol (0.8 $\mu \mathrm{g})$, alpha-tocopherol ( $8.0 \mu \mathrm{g})$, cholecalciferol $(0.8 \mu \mathrm{g})$ and ergocalciferol $(0.8 \mu \mathrm{g})$. (A) Channel 1, UV detection at $325 \mathrm{~nm}$ for retinol and $265 \mathrm{~nm}$ for cholecalciferol and ergocalciferol; (B) Channel 2, fluorescence detection at $\lambda_{e x}=288 \mathrm{~nm}$ and $\lambda_{e m}=332 \mathrm{~nm}$ for alpha-tocopherol

\section{Sample preparation}

The edible fish tissue was filleted with the skin left on and homogenized using kitchen homogenizer for $3 \mathrm{~min}$. Alkaline hydrolysis: An aliquot of the homogenized fish tissue sample $(1.00 \mathrm{~g})$ was weighed into a glass tube with a screw cap. Two $\mathrm{ml}$ of $1 \%$ methanolic solution of L-ascorbic acid and $5 \mathrm{ml}$ of $1 \mathrm{M}$ methanolic solution of potassium hydroxide were added. Each time at least three parallel samples were prepared and subjected to saponification at $80^{\circ} \mathrm{C}$ for $20 \mathrm{~min}$.

Liquid-liquid extraction: The fat-soluble vitamins from the hydrolysate were extracted twice with $4 \mathrm{ml} n$-hexane by vortexing for $5 \mathrm{~min}$. The combined extracts were evaporated to dryness under gentle stream of nitrogen. Finally the dry residue of the fat soluble vitamins fraction was reconstituted in $200 \mu 1$ methanol and $20 \mu 1$ aliquot was injected in the HPLC column.

Standards and quantification: Stock standard solutions of each analyte $(1.0 \mathrm{mg} / \mathrm{ml})$ were prepared in $100 \%$ methanol and stored at $-20^{\circ} \mathrm{C}$ away from light. Working solutions were prepared from these solutions and diluted with methanol prior to analysis. In all the cases, the stock solution was analyzed together with the samples. Analyte concentrations in samples were estimated on the basis of peak areas. All samples were analyzed in triplicate. Retinol, alpha-tocopherol, cholecalciferol, and ergocalciferol contents were cited as means \pm standard deviation.

\section{RESULTS}

Chromatography: Good separation of the analytes, in less than $20 \mathrm{~min}$, was achieved using methanol/water 93/7 (v/v)

\section{Method validation}

Linearity: Calibration curves, based on analyses of six dilutions of the corresponding standard, were obtained by least-squares linear regression analysis of the peak area of analytes versus their concentration. The following equations were obtained: $\mathrm{y}=1.91^{\mathrm{e} 006} \mathrm{x} \mu \mathrm{g}$ for retinol; $\mathrm{y}=7.73^{\mathrm{e} 006}$ $\mu \mathrm{g}$ for ergocalciferol; $\mathrm{y}=3.37^{\mathrm{e} 006} \mu \mathrm{g}$ for cholecalciferol, and $2.41^{\mathrm{e} 006} \mu \mathrm{g}$ for alpha-tocopherol. The method was linear up to $3.2 \mu \mathrm{g}$ for retinol, cholecalciferol and ergocalciferol, and up to $32 \mu \mathrm{g}$ for alpha-tocopherol. Correlation coefficients ranged from 0.997 to $0.998(\mathrm{n}=3)$.

Precision: Six replicate determinations of a fish tissue sample were performed under optimum conditions to determine repeatability. Three replicate analyses of the same sample were made over a period of 3 consecutive days to determine reproducibility. Table 1 shows precision results. The relative standard deviations (RSDs) of the repeatability and the reproducibility are $\leq 10 \%$.

Recovery: Recovery rates were determined by comparing the observed analyte concentration in the extracted sample to those with a standard addition of the analyte into the sample. Analytical recovery after hydrolysis, consequent extraction and chromatography exceeded $76 \%$ for retinol and ergocalciferol, 93\% for alpha-tocopherol, $83 \%$ for cholecalciferol.

Verification: The practical applicability of the method was assessed by the analysis of 20 fish tissue samples (Fig. 2). Retinol contents ranged from 6.9 to $142.3 / 100 \mathrm{~g}$ raw tissue, alpha-tocopherol contents from 308.0 to $1534.1 / 100 \mathrm{~g}$, and cholecalciferol contents from 5.8 to $11.4 / 100 \mathrm{~g}$ raw tissue. 

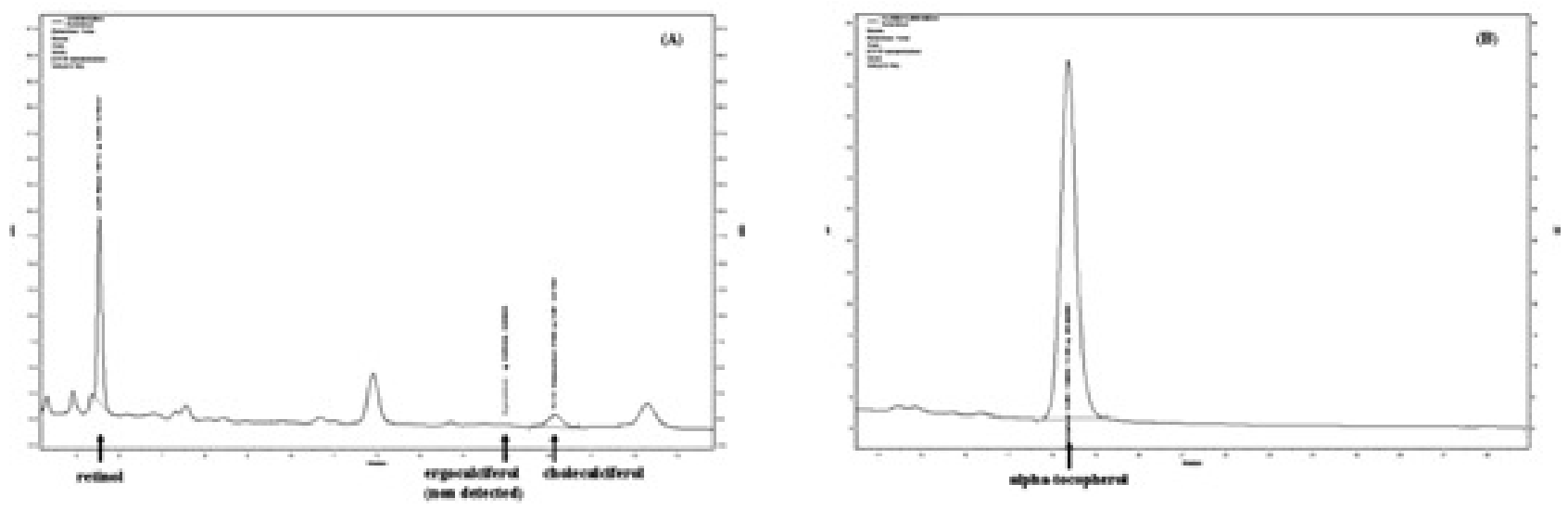

Fig. 2. HPLC chromatograms for determination of retinol, alpha-tocopherol, cholecalciferol in a sample of fish tissue homogenate. Ergocalciferol is non-detectable in the sample. (A) Channel 1, UV detection at $325 \mathrm{~nm}$ for retinol and $265 \mathrm{~nm}$ for cholecalciferol and ergocalciferol; (B) Channel 2, fluorescence detection at $\lambda_{e x}=288 \mathrm{~nm}$ and $\lambda_{\text {em }}=332 \mathrm{~nm}$ for alpha-tocopherol

\section{DISCUSSION}

There have been many studies of optimum saponification conditions for the extraction of retinol, alpha-tocopherol, ergocalciferol, and cholecalciferol from fish tissues $(9,12,16)$. The large scale extraction methods are expensive in terms of apparatuses required, cost of solvents, and time. This is why we decided to develop a small-scale method of the type described by Sanchez-Machado (11). We used smaller sample amounts $(1.0 \mathrm{~g})$ in comparison with others $(10,12)$. To determine the optimal hydrolysis conditions we performed preliminary studies with different concentrations of $\mathrm{KOH}$ in methanol ( $1 \mathrm{M}$ and $0.5 \mathrm{M})$. In order to preserve the fat-soluble vitamins from oxidation we tested two antioxidants: BHT and ascorbic acid. The findings indicate that better results are obtained with $1 \mathrm{~g}$ of sample, $1 \mathrm{M} \mathrm{KOH}$ in methanol, and $1 \%$ ascorbic acid solution as antioxidant. In order to achieve better resolution of the fat-soluble vitamins of interest, we tested several compositions of the mobile phase: 100\% methanol; 40/60 acetonitrile/ methanol (v/v); 60/40 acetonitrile/methanol (v/v), and 97/3 methanol/water $(\mathrm{v} / \mathrm{v})$. Best resolution between vitamins $\mathrm{D}_{2}$ and $\mathrm{D}_{3}$, which are structurally very similar, was achieved using $97 / 3 \mathrm{methanol} /$ water $(\mathrm{v} / \mathrm{v})$ at a flow rate $1.0 \mathrm{ml} / \mathrm{min}$. Published methods indicate the wide use of both normal and reverse phase columns $(10,16)$. Using conventional (RP C18) and low cost chromatographic column at column temperature $25^{\circ} \mathrm{C}$ we obtained satisfactory separation of four tested fat soluble vitamins.

The linearity of standard curves covers wide concentration range in concordance with the published level of the tested analytes in the edible tissue of different fish species. In all cases, the relationships between the concentration and peak areas were linear with coefficients of variation greater than 0.995 .

The precision study was comprised of repeatability and reproducibility studies. A total of six replicate determinations of a sample were performed under optimum condi- tions to determine repeatability. Three replicate analyses of the same sample were made on three consequent days to determine reproducibility. The relative standard deviations (RSDs) of the repeatability and the reproducibility and the estimated analytical recovery indicate that the present method can be used for quantitative analyses of the above mentioned fat-soluble vitamins in fish tissue.

Examination of the practical applicability of the method on real fish tissue samples reveals comparable results with the data given by others $(2,4,5,7,8,10,12,14,15)$.

\section{CONCLUSIONS}

The present method has analytical characteristics (with respect to precision and recovery) allowing its use for quantitative analyses of retinol, alpha-tocopherol, cholecalciferol, and ergocalciferol in edible fish tissue. Performing sample preparation and analyte extraction in a single reaction tube gives the method the advantage of minimizing manipulation. The method is easy, economical and convenient for routine determination of retinol, alpha-tocopherol, and cholecalciferol content in fish tissues.

\section{ACKNOWLEDGMENTS}

This study was financed by the National Science Fund, Ministry of Education and Science of Bulgaria (Project DVU 440/2008).

\section{REFERENCES}

1. Náî đí èê ì åôî äè çà õèàèái í è èçñëåäâà èÿ, Í àöè î ìàåí öåí oúð î î õèãèåí à, ì åäèöèí ñêà åêî êî ãèÿ è õðàí åí å, 1999, 1

2. Ahmadnia A., M.A. Sahari, M. Barzegar, S.J. Seyfabadi and M. Abdollahi, Vitamins Contents of some Commercially Important Fish Species from 
South Caspian Sea, Am.-Eur. J. of Sust. Agr., 2008, 2(3): 285-293.

3. Byrdwell W.C., J. DeVries, J. Exler, J.M. Harnly, J.M. Holden, M.F. Holick, B.W. Hollis, R.L. Horst, M. Lada, L.E. Lemar, K.Y. Patterson, K.M. Philips, M.T.

Tarrago-Trani, and W.R. Wolf, Analyzing vitamin D in foods and supplements: methodologic challenges, Am. J. Clin. Nutr., 2008, 88:554S-7S.

4. Danish Food Composition Databank, Department of Nutrition, National Food Institute, 2007.

5. Dias M.G., Sanchez M.V., Bartolo H., Oliveira L. Vitamin content of fish and fish products consumed in portugal, Electr. J. Env. Agric.and food chem., 2003, 4: 510-513.

6. Gören A.C., G. Bilsel, M. Bilsel, Rapid and simultaneous determination of 25-OH-vitamin $\mathrm{D}_{2}$ and $\mathrm{D}_{3}$ in human serum by LC/MS/MS: Validation and uncertainty assessment, J. Chem. Metrl., 2007, 1:1 $1-9$.

7. http://fn.cfs.purdue.edu/fish4health/HealthBenefits/ shad(American).pdf

8. http://wholefoodcatalog.info/food/horse_mackerel(raw)/nutrients/

9. Huo Ji-Zeng, H.J. Nelis, P. Lavens, P. Sorgeloos, and A.P. De Leenheer, Determination of Vitamin E in Aquatic Organisms by High-Performance Liquid Chromatography with Fluorescence Detection, Anal. Biochem., 1996, 242, 123-128.

10. Kuhnlein H.V., Barthet V., Farren A., Falahi E., Leggee D., Receveur O., Berti P., Vitamin
A, D, and E in Canadian Arctic traditional food and adult diets, J. Food Comp. Anal., 2006, 19: 495-506.

11. Lopez-Cervantes J., D.I. Sanchez-Machado, N.J. Rios-Vazquez, High-performance liquid chromatography method for the simultaneous quantification of retinol, $\alpha$-tocopherol, and cholesterol in shrimp waste hydrolysate, J. of Chrom. Aq., 2006, 1105, 135-139.

12. Ostermeyer U., T. Schmidt, Vitamin D and provitamin D in fish, Eur. Food Res. Technol., 2005.

13. Rao Sunita D., Raghuramulu N., Vitamin D and its related parameters in fresh-water wild fishes, Comp. Biochem. Physiol., 1995, 111A, 191-198.

14. Ribarova F., R. Zanev, S. Shishkov, N. Rizov, a-Tocopherol, fatty acids and their correlations in Bulgarian foodstuffs, J. of Food Comp. and Anal., 2003, 16, 659-667.

15. Roos N., Chamnan C., Loeung D., Jakobsen J., Jhilsted S.H., Freshwater fish as a dietary source of vitamin A in Cambodia, Food Chem., 2007, 103, 1104-1111.

16. Salo-Väänänen P., V. Ollilainen, P. Mattila, K. Lehikoinen, E. Salmela-Mölsä, V. Piironen, Simultaneous HPLC analysis of fat-soluble vitamins in selected animal products after small-scale extraction, Food Chem., 2000, 71, 535-543.

17. Sundl I., Murkovic M., Bandoniene D., Winklhofer-Roob B.M., Vitamin E content of foods: Comparison of results obtained from food composition tables and HPLC analysis, Clin. Nutr., 2007, 26, 145-153. 